\title{
Syndrome of Inappropriate Antidiuretic Hormone Secretion
}

National Cancer Institute

\section{Source}

National Cancer Institute. Syndrome of Inappropriate Antidiuretic Hormone Secretion. NCl Thesaurus. Code C3988.

A syndrome characterized by abnormal secretion of antidiuretic hormone in conjunction with neoplastic growth occurring anywhere in the body. 